\title{
Participação infantil e debate democrático: aproximações pelo campo da educação infantil
}

Resumo: Este estudo visa discutir como a temática da Democracia e seus princípios se apresentam no cenário acadêmico e político pedagógico da Educação Infantil a partir do contexto histórico e político-social brasileiro contemporâneo. Trata-se de uma discussão multidisciplinar, que se respalda teoricamente, principalmente, nos escritos de Peter Moss (2009, 2013), Jens Qvortrup (2010), Sarmento, Fernandes e Abrunhosa (2007) e Jan Masschelein e Maarten Simons (2014), para ressignificação das categorias, e para que o debate democrático estabeleça relações com cenário educacional de crianças de 0 a 6 anos de idade, a partir de algumas problematizações. Aborda-se a democratização da e na Educação Infantil, fazendo a diferenciação entre elas. Apontamos possibilidades para que as discussões avancem no sentido de democratizar a democracia com a Educação Infantil, e que essa garanta o protagonismo da participação infantil.

Palavras-chave: Educação Infantil. Política Educacional. Democracia. Participação Infantil.

\section{Child participation and democratic debate: approximations by the field of early childhood education}

Abstract: This study aims to discuss how the theme of Democracy and its principles are presented in the academic and political pedagogical scenario of Early Childhood Education from the contemporary Brazilian historical and political-social context. It is multidisciplinary discussion, theoretically supported mainly by the writing of Peter Moss (2009), Jens Qvortrup (2010), Samernto, Fernandes and Abrunhosa (2007) and Masschelein and Maarten Simons (2014), for the re-signification of the categories, and for the democratic debate to establish relations with the educational scenario of children from 0 to 6 years of age, based on some problematizations. We approach the democratizations of and in Child Educations, differentiating between them, and we point out possibilities for the discussions to move forward in the sense of democratizing democracy with Early Childhood Education, and this guarantee the protagonism of child participation.

Keywords: Early Childhood Educations. Educational politics. Democracy. Child Participation.

I Doutoranda em Educação Universidade Federal do Rio Grande do Sul. Professora da Universidade Federal do Maranhão - UFMA. E-mail: fabicanavieira@hotmail.com

2 Doutora em Educação pela Universidade Estadual de Campinas. Professor Titular da Universidade Federal do Rio Grande do Sul. Email: licabarbosa@ufrgs.br 


\section{Introdução}

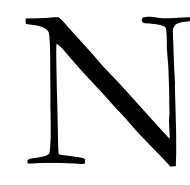

o ano de 2013 o Brasil teve os primeiros sinais de que as mobilizações sociais e suas pautas reivindicatórias apresentar-se-iam de maneira diferenciada no século XXI. Viu-se a efervescência da agitação, e por vezes, da mobilização social de uma sociedade que luta por suas concepções políticas, por direitos e políticas públicas que garantam não só os princípios democráticos, mas o ideal de vida e consumo propagados tanto pelos agentes políticos quanto pelo mercado-mídia, o que, por vezes, unificou pautas entre lados distintos da ideologia política, e até pareceu borrar as fronteiras das classes sociais. Todavia, o contexto político-social no qual nos inserimos, precisamente desde o início de 2016, tem, ao contrário disso, cindido o país, dando corpo ao espírito de caos e tirado do fundo do baú os fantasmas que nos assombram na esfera do cerceamento dos direitos sociais e trabalhistas da população brasileira.

É no contexto político-econômico que forçou um "impedimento" presidencial e tomou o governo, apresentando-se como antagonista político-ideológico de tudo que vinha sendo construído em mais de uma década, que nos encontramos nesse momento. E uma das principais áreas atingidas pela política de contingenciamento do (des)governo Michel Temer - PSDB, é a Educação, em seus diferentes níveis e modalidades. Dento desta área as primeiras medidas da política antissocial assumida, foram: o congelamento dos recursos destinados às áreas sociais; a tentativa de implementação do Projeto "Escola sem Partido"; alterações na Base Nacional Comum Curricular - BNCC e a Reforma do Ensino Médio. Mas, infelizmente, não se tem perspectiva que tais medidas parem por aí, - legitimando os processos de descontinuidade e desconstrução da educação pública que vinha sendo arduamente edificada -, objetivo almejado pelo atual staff que gesta a res publica.

Alguns estudos que buscam esclarecer teoricamente como circunstâncias caóticas atingem o campo educacional têm se utilizado de diferentes tipos de metáforas, como forma de ilustrarem os movimentos oscilantes, abalos e tremores que atingem a área, principalmente a Educação Infantil, que parece ter uma sensibilidade mais aguçada às inconstâncias -, decorrente das dificuldades inerentes a sua história de luta e constituição, até seu reconhecimento e consolidação como primeira etapa da educação básica. Analogias com a mitologia e os fenômenos da natureza já foram usadas para caracterizarem os cenários de instabilidade que de tempo em tempo nos rodam, tais como: "O mito do Sísifo" (ROSEMBERG, 2003), "fazer um mapa em meio ao terremoto" (CAMPOS, 1998) ou o caos do "Olho do furacão" (CANAVIEIRA, 2010).

Mas, nesse momento, em que somos interpelados pelos acontecimentos do presente, pelos fenômenos sociais da contemporaneidade, a ter/dar algumas respostas explicativas, e apontar algumas possibilidades de enfretamento à crise generalizada, construir uma "meta-fora", como algo que pela distância 
narrativa, estética ou discursiva, diz, por analogia, o que se torna difícil descrever literalmente, parecer não caber. É como buscar do lado de fora, e, meio ao caos, na distância, o que precisa ser dito pelo lado de dentro, pela proximidade.

A conjuntura histórica tem sinalizado que mudanças político-sociais estão em curso, e elas têm demandado uma revisão de nosso projeto de sociedade e de formação humana, solicitando a tomada de posição por princípios, que a nosso ver, salvaguardem o respeito à dignidade humana, justiça social, às relações solidárias. Diante dessas circunstâncias, faz-se imprescindíveis aos debates do campo educacional, as discussões em torno da formação, ação política e fundamentação dos princípios democráticos no cotidiano educacional. É nesta perspectiva que este artigo se inscreve, pela inquietação do seguinte questionamento: como a Educação Infantil e as crianças pequenas tomam parte do debate democrático?

Este artigo faz parte de uma pesquisa em construção, e se fundamenta em uma perspectiva multidisciplinar para discutir e ressignificar as perspectivas democráticas e seus temas correlatos. Almeja-se demonstrar que é possível construir pontes entre os estudos e agenda pública da participação e cidadania infantil e o debate político democrático contemporâneo. Para (re)ssignificação destas categorias junto ao cenário educacional de crianças de 0 a 6 anos de idade este estudo se fundamenta nos escritos de Peter Moss (2009), Jens Qvortrup (2010), e em outras/os autoras/es do campo da Sociologia da Infância, como Fernandes (2009), Agostinho (2010) e Trevisan (2014).

\section{Democratizar com a Educação Infantil}

A democracia "já foi” patriarcal, racista e segregacionista em seus primórdios tempos de ágora grega, que mesmo sendo direta e participativa, era para poucos. Ainda hoje ela pode ser pensada por suas falhas, mas também, como valor universal, como anunciado por Nelson Coutinho (1980). Isso demostra que desde sua gênese houve/há a necessidade dos conceitos e práticas democráticas serem ressignificadas constantemente. Aqui, não faremos a defesa de que as vivências de situações educativas, pedagogicamente democráticas, conduzam ao aprendizado da democracia em seu sentido coletivo e público, mas, de que se vivência de práticas democráticas, forem praticadas em certa área, torna-se mais fácil estendê-la a outras. Sendo, a prática da democracia em todos os campos, âmbitos e tempos da vida, a única maneira de avançar no processo de construção da democracia.

Por vezes, soa incomum falar de democracia e participação, como prática democrática, quando se está fazendo referência à educação de crianças de 0 a 5 anos de idade, e assim conjecturar o que essa abordagem vislumbra como perspectiva epistemológica, mas também em termos de uma práxis. Nesse sentido, amparamo-nos nas proposições de Dahlberg; Moss e Pence (2003, p.87) quando dizem que "o que pensamos serem essas instituições determina o que fazemos e o que acontece dentro delas".

Para esses autores, a instituição de educação e cuidado dedicada à primeira infância tem que desempenhar o papel de um fórum na sociedade civil que favoreça a visibilidade, a inclusão e a participação ativa da criança pequena na sociedade civil, "onde crianças e adultos se reúnem e participam juntos de projetos 
de importância cultural, social, política e econômica" (ibidem, p. 17). Partindo dessa leitura questionamos se é possível vislumbrar a Educação Infantil brasileira como um locus de práticas democráticas?

É a partir da procura por resposta a tal questionamento que vamos ao encontro de formas de pensar a participação infantil em articulação direta com sua ação pública e política de forma mais ampliada, enquanto cidadania ativa (BENVIDES, 2003) a ser vivenciada pelas crianças dentro da Educação Infantil. Valendo-nos, dos fundamentos da ciência política, e posteriormente da filosofia, sem esquecer a sociologia, para abordar os princípios político-democráticos no campo educacional, apresenta-se, mesmo que de forma ainda incipiente, que os embates passam pela disputa em torno de um novo significado de democracia. A exemplo do que foi enfatizado por Jan Masschelein e Maarten Simons (p. 89, 2014),

\begin{abstract}
A democracia não devia ser conceituada como um regime político ou governamental (...) no meio de outros regimes menos democráticos, mas como a constituição de um sujeito político através de manifestações e demonstração de injustiças ou de algo "errado". Para ele, a democracia trata do poder daqueles que não têm poder, aqueles que não têm qualificação em uma ordem social ou governamental particular, aqueles que não compartilham o que deve ser compartilhado a fim de se tornar parte de uma sociedade, comunidade ou ordem social, quando essas pessoas "não qualificadas" ou "incompetentes" ainda assim intervêm, elas instalam um dissenso, ou seja, elas demonstram e verificam que elas são intelectualmente iguais no próprio ato de intervenção, e que elas são competentes em vista do comum do qual elas são, não obstante, excluídas.
\end{abstract}

A educação da pequena infância em espaços públicos e coletivos continua sendo uma construção social e política, edificada cotidianamente, que precisa ser realizada nos diferentes espaços, âmbitos e por diferentes agentes, - o que também se constitui em um dos objetivos deste artigo -, e na qual, se defende que as crianças, de todas as idades, sejam partícipes. "Acreditamos sim, que (...) ocorre a construção da igualdade política neste local de acolhimento da diversidade que é a educação infantil (BARBOSA, 2009, p.174)”.

Desde a Constituição Federal de 1988 - que instituiu a Educação Infantil como direito das crianças e de seus responsáveis, e como dever do Estado (Artigos 208 e 205 respectivamente), pesquisadoras/es e profissionais da área têm se dedicado ao debate acerca da democratização do acesso à Educação Infantil pelas crianças de 0 a 6 anos de idade, e de qualificar a inclusão da primeira etapa educacional como um direito social importante. Foi no cercamento dessas questões que o debate político se circunscreveu durante algum tempo. Destarte, as discussões preponderavam mais em torno da democratização da Educação Infantil do que da democratização na Educação Infantil. Assim como nas demais etapas educacionais, quando o foco é democratização na Educação, tematiza-se a democratização da gestão, do trabalho do/a gestor/a e da gestão político-pedagógica; por vezes a participação das famílias e comunidades também é preponderante, em detrimento da participação estudantil e das crianças.

Conforme constatado por Sarmento (2007) as crianças parecem sofrer de diferentes formas de invisibilidades sociais, dentre elas a (in)visibilidade cívica - que nega-lhes o papel de ator político concreto. Confinadas aos espaços sociais controlados pelos adultos, isso tem gerado como consequência o entendimento de que estão privadas do exercício do direito político, aqui, no caso, o de participação. Questões pouco visíveis nas discussões pedagógicas e na agenda da política educacional brasileira até há pouco tempo. 
Para Sarmento, Fernandes e Abrunhosa (2007, p.54) as políticas para a infância e as políticas educativas estão mutuamente imbricadas, as duas integram a política social se inserindo no quadro geral de construção do espaço público, no qual as opções fundamentais de natureza simbólica e de prática política se baseiam no modo como o Estado se relaciona com a economia e a estrutura social, que por sua vez, refletem opções ideológicas e interesses que se exprimem e direcionam tanto as políticas para infância quanto as políticas educacionais direcionadas às crianças, e chegam direta ou indiretamente até as próprias crianças.

[..] as concepções da infância dominantes no momento da decisão política influenciam decisivamente os programas de política educativa: esta não é, apesar da ilusão da autonomia do espaço pedagógico que é comum a decisores políticos e a professores, por efeito conjugado da profunda institucionalização da educação escolar e da efectiva autonomia relativa da escola ante a economia [...] (SARMENTO, ABRUNHOSA, FERNANDES, 2007, p. 54, sic)

Cabe registrar que, segundo Barbosa (2009), só há pouco tempo os/as operadores/as da área de Educação Infantil no Brasil foram credenciados para a interlocução dentro dos sistemas educacionais, antes eram, e talvez continuem sendo, um campo marginalizado tanto no âmbito das práticas e teorização, quanto da discussão da política educacional nacional. Entretanto, apesar de ser "estreante" (Barbosa, 2009) no campo educacional, não precisou/precisa se submeter a todas as regras das demais etapas da educação básica, nem aceitar nenhuma forma de ostracismo.

Em nossa sociedade há uma visão familiarista da educação das crianças pequenas como algo privado. Muitas famílias preferem que as crianças fiquem com as avós, empregadas domésticas, os irmãos ou outros familiares, ainda que despreparados, pois não confiam na creche ou esta tem um modelo de funcionamento que não é compatível com o da família. Os filhos ainda são vistos como "cidadãos privados", mas é preciso pensar que as crianças são públicas; a criança pode ser vista como um ser público, da sociedade, do país. (BARBOSA, 2009, p. 173).

$\mathrm{Na}$ atualidade, apesar da consagração jurídica dos direitos das crianças, sua participação política para além dos assuntos de seus contextos de vida, e mesmo nesses, enquanto possibilidade de tomada de decisão por parte das crianças, não aparecem normalmente na agenda educativa em termos de um amparo legal, quando muito, é tratada como uma dimensão didático-metodológica das pedagogias ativas (SARMENTO, ABRUNHOSA, FERNANDES, 2007). No entanto, construir dispositivos concretos que marquem nossa tomada de decisão no sentido de garantir a participação política como usufruto dos direitos políticos, já conquistados, pode apresentar-se como uma das mais interessantes propostas reabilitadoras do papel cívico e transformador da escola pública.

Contudo, deixar que as crianças falem e escutar suas vozes ainda não é o suficiente para o pleno reconhecimento de sua inteligibilidade para o exercício de sua cidadania - ainda que nem isso tenhamos conquistado plenamente no campo da ação -, depende-se que os processos de participação social estejam efetivamente presentes de forma sistemática na organização do seu cotidiano, em especial no âmbito das instituições educativas da qual fazem parte, e que podem apresentar contextos privilegiados para o desenvolvimento de uma cultura democrática de respeito à opinião das crianças, já que, contemporaneamente, são os espaços "privilegiados" de vivência da infância.

Tem-se então, na fala de Peter Moss (2009) um respaldo que nos permite pensar, em paralelo ao Princípio Político da/na Educação Infantil brasileira, instituído nas Diretrizes Curriculares Nacionais para 
Educação Infantil - DCNEI (1999, 2009), que versa sobre “dos direitos de cidadania, do exercício da criticidade e do respeito à ordem democrática (BRASIL, 2009, p.8)", pois coteja os condicionantes pautados por esse Princípio: práticas democráticas, participação como cidadania, a garantia das diversidades e as relações de poder inerentes à Educação Infantil. Nessa perspectiva,

Por que práticas democráticas são tão importantes, no geral e na educação infantil? A necessidade pode ser posta em poucas palavras. Participação democrática é um critério importante de cidadania: é um meio pelo qual crianças e adultos podem se envolver com outros na tomada de decisões que afetam eles mesmos, grupos dos quais eles são membros e a sociedade como um todo. É também um meio de resistir ao poder e à sua vontade de governar, e às formas de opressão e injustiça que emergem do exercício descontrolado do poder. Por fim, mas não menos importante, a democracia permite que a diversidade prospere. Ao fazer isso, oferece o melhor ambiente para a produção de pensamentos e práticas novas. (MOSS, 2009, p.419).

Há diferentes passagens nos escritos de Peter Moss (2009) que auxiliam a ponderar a potencialidade dos documentos legais no sentido da consolidação de práticas democráticas na Educação Infantil. Segundo o autor, o primeiro passo para a construção de práticas democráticas na área se inicia com a intencionalidade por um direcionamento nessa perspectiva. "É improvável que a instituição de educação infantil como um local para a prática democrática ocorra por acaso. É necessário que haja intenção, uma escolha precisa ser feita, e isso requer condições favoráveis” (MOSS, 2009, p. 426). Com a determinação política de afirmar os ideais democráticos como decisão de um caminho a seguir "enquanto um valor nacionalmente aceito" (ibidem. p.423), ao invés de outros.

Nestes termos, defende-se que se inicie o debate democrático na Educação Infantil pela tomada de decisão dos valores políticos que regerão as práticas pedagógicas. Aqui fazemos uma escolha declarada de que os valores a serem buscados são os democráticos e éticos, de justiça e igualdade nas diversidades, exercidos pela participação ativa (social, política e popular) com pluralismos e liberdade. Que se respalda tanto em ordenamentos legais como em estudos científicos, que nos permitem pensar a pertinência desses valores e sua concretização através de práticas democráticas com a Educação Infantil, dando ênfase à participação infantil.

\section{A Participação Infantil como princípio democrático}

No exercício de cercar o tema da participaşão infantil, depara-se com muitas possibilidades de abordagem da temática, parte das referências bibliográficas das pesquisas e artigos que vêm apresentando o tema (SARMENTO (2007 e 2008); FERNANDES (2009); TOMAS (2011); TREVISAN (2014); AGOSTINHO (2010) se filiam claramente à abordagem da Sociologia da Infância, por onde também começamos a trilhar o caminho pelo tema, que de início apresenta duas portas de entrada. A primeira, oriunda do desvelamento das categorias sociológicas que abrem as discussões da volta do ator social, que enseja a reflexão sobre os papéis sociais e coloca em cena as posições desses atores, com protagonismo. E a segunda entrada, dar-se pelo âmbito da perspectiva dos direitos das crianças.

Percorrendo pela primeira entrada no assunto da participação infantil, pode-se adentrá-la pela discussão dos conceitos sociológicos que se apresentam ao campo da Sociologia Infantil, como o conceito de agency (agência) enquanto capacidade de ação, ação social (GIDDENS 1999 e 2003), mas não só. Como agente de 
um campo, com propriedade de posições (BOURDIEU, 1968), isso em apenas duas das abordagens sociológicas mais clássicas que trabalham com essa categoria. Em um olhar mais contemporâneo dentro da teoria social, agência significa dispor de poder e capacidades que, através de seu exercício, tornam o indivíduo uma entidade ativa que constantemente intervém no curso dos acontecimentos à sua volta (BARNER, 2000).

Correlata a discussão da agência, tem-se o debate oriundo das categorias de ação social e ação coletiva pontuadas também pela sociologia de Antony Giddens (1999, 2003), mas de forma mais próxima a nós, dos Estudos Sociais da Infância e das Crianças, como por exemplo, pela pesquisa de Coutinho (2010) sobre a ação social dos bebês. Barbosa, Delgado e Tomás (2016) fazem um acompanhamento da trajetória do debate desses conceitos fundantes dentro da área dos Estudos da Infância e das Crianças, e ao fazê-lo trazem um posicionamento da francesa Régine Sirota na diferenciação destas categorias,

Quanto aos conceitos de agência, ação e ator social, Régine Sirota (2011) identifica a criança como ator social no mundo francófono e a agência da criança no mundo anglófono. Não são termos equivalentes, pois a agência toma uma noção mais ampla, porque não se trata apenas da capacidade de ação social da criança, mas subentendem-se os efeitos dessa mesma ação na definição da situação para os diferentes atores (BARBOSA; DELGADO; TOMÁS, 2016, p. 2016).

É perceptível que seja possível deter-se ao debate sobre a participação infantil a partir das diferentes escolas do pensamento sociológico, nas quais cada uma dessas categorias, destacadas acima, são abordadas. Fazer tais distinções de filiações teóricas torna-se fundamental para o desvelamento teórico-metodológico em que cada pesquisa e debate se inserem. Todavia, a Sociologia da Infância nos aproximou destas categorias, auxiliando na formulação de uma outra/nova gramática para a área dos Estudos da Infância, sem nem sempre nos apresentar tais filiações clássicas. Sendo assim, por vezes, conceitos como participação, agência, ação coletiva e protagonismos passam a ser utilizados de forma indiscriminada, até como sinônimos. Foi essa forma dissociativa do uso do conceito de participação infantil e o (des)entendimento quanto ao significado dessas terminologias que nos instigaram a submergir no assunto.

Essa indefinição conceitual constituiu-se em uma das nossas inquietações, mas também é um ponto de preocupação de outros pesquisadores. Dentre tantos, ficaremos com as abordagens de Pires e Branco (2007) e de Trevisan (2014), essa última nos diz:

Assim, importantes distinções seriam necessárias entre participação, consulta, ação coletiva, visibilidade ou protagonismo. A participação num sentido mais significativo deveria, assim, levar a transformações e influências nos contextos de vida das crianças, refletindo também sobre as esferas públicas e privadas onde as crianças sejam vistas não apenas como indivíduos, mas como coletivo (TREVISAN, 2014, p. 46).

No pensamento de Pires e Branco (2007), que têm preferência pelo debate da categoria protagonismo, há uma ressalva acerca do paradoxo de como uma criança pequena, com "autonomia limitada" pelas diferentes formas de dependências e maturidade biopsíquica, passa a ser defendida como protagonista e participante dos processos sociais. Para responder a esse questionamento que os autores se fazem, eles realizam um resgate da história social da infância dando destaque à superação dos pontos de vista baseados na incapacidade e incompletudes infantis e, então, apresentam um paralelo entre os conceitos de protagonismo e participação, que nos interessa. 
Para eles, o termo protagonista tem origem etimológica na palavra grega protagonistés, que significa ator principal de uma peça teatral, ou aquele que ocupava lugar destacado em um acontecimento (PIRES e BRANCO, 2007, p. 321). As restrições e polêmicas mais comuns ao uso do termo, nos estudos sociológicos, se devem a fatores de ordem política, uma vez que a utilização da palavra participação remete a uma abordagem mais democrática de ação social, sem colocar em destaque um protagonista em especial. Os autores destacam uma maior facilidade do uso do termo participação no emprego com as crianças, tanto para o uso por elas próprias, por ser uma palavra de uso corrente em nossa língua, quanto pela possibilidade explicativa do que é participação enquanto envolvimento em processos decisórios.

A segunda forma de percorrer o tema da participação tem sido pelo viés do debate da garantia dos direitos das crianças, via inclusão delas nas políticas públicas, nas discussões de cunho político e econômico, mas principalmente pelo respaldo jurídico-legalista que apresenta o estatuto de cidadania das crianças. Nessa abordagem a Convenção das Nações Unidades sobre os Direitos das Crianças - CDC (1989) ganha papel imprescindível.

Mas antes de entrar pela segunda porta, a escolhida, é importante fazer duas ressalvas. A primeira, para deixar claro que os dois caminhos não se anulam ou são incompatíveis teoricamente, ao contrário. Acredito que percorrer um leva ao outro, e vice-versa. A escolha por apenas um desses caminhos, nesse momento, se trata muito mais pela otimização do tempo-espaço que cabe a este artigo. A segunda questão que gostaria de considerar é que, em algumas abordagens (LANSDWON 1998, 2005; FRANZONI, 2015), o tema da participação infantil ganha tamanha centralidade que não apresenta mais associações teóricas. A participação infantil é tida como um valor em si mesma (TREVISAN, 2015).

As pesquisas que se inscrevem sob a insígnia da participação social como uma perspectiva mais abrangente de discussão, seja a participação de crianças ou de adultos, caracterizam o tema por uma perspectiva multidimensional, que não se constitui em um fenômeno novo. A socialização das crianças via inserção direta no meio social a qual fazem parte, assumindo papéis sociais, está/esteve presente historicamente em diversos grupos sociais em diferentes espaços-tempo (FERNANDES, 2009; QVORTRUP 2015). Contudo, as formas e o significado atribuídos a essas diferentes maneiras de participação são o alvo de um redirecionamento da maneira de conceber a participação infantil.

Considera-se então, a existência de diferentes tipos, níveis e maneiras de participação, e que cada uma delas condicionará a uma significação distinta do conceito de participação. Há escalas que classificam esses tipos e níveis, para a participação social de uma forma mais generalizada, como apontado por Bordenave (1994) no livro "O que é Participação", e por autores específicos do âmbito da participação infantil (FERNANDES, 2009; HART, 1992; LANWDSON, 2005). Acompanhar esse movimento classificatório revela a importância de qualificar o tipo de participação infantil que tem sido abordada, tanto nos ordenamentos legais que instituem políticas, quanto nas pesquisas acadêmicas, demonstrando que tão relevante quanto o conteúdo é a forma como ele é operado.

Um dos exemplos dessa classificação é dado pela Escada de Participação, segundo Hart (1992), com graus que seguem dos níveis não participativos, tidos como manipulatórios ou decorativos, até o degrau mais 
elevado de participação infantil, que revela a esfera de parceria entre adultos e crianças em pé de igualdade. O autor que apresenta um dos trabalhos pioneiros na área de estudo da participação infantil, afirma não existir sociedade que ofereça, o tempo todo, a máxima oportunidade de participação para as crianças, considerando principalmente que o sistema de ordenamento político-social que daria sustentação a essa vivência seria o sistema democrático, que carrega em si a possibilidade contraditória da não participação também como um direito. Assim, espera que diversos grupos se revezem em oportunizar os diferentes tipos de participação infantil de sua escala.

Sendo assim, levando em conta os níveis de participação por uma perspectiva crítica, sem hierarquizá-los, mas tendo-os de forma relacional, e perseguindo os estágios de autonomia participativa, autogestão e cidadania, partimos para apresentar os conceitos de participação e participação infantil. Para tanto, leva-se em consideração a ressalva feita na pesquisa de Kátia Agostinho (2010) sobre os deslizamentos semânticos que essas categorias apresentam. Como, por exemplo, o significado etimológico da palavra participação em latim, pois, como vemos, em dois autores há sutis diferenças de conotação. Para Tomás e Gama (2011), a palavra latina participar e denota fazer saber; todavia, de pronto nos alertam que o "conceito tem múltiplos significados que se intersectam entre si” (p. 3).

Para Bordanave (1994, p. 22), participares e originou da expressão partem capere, que quer dizer tomar parte. $\mathrm{O}$ autor continua sua explicitação do conceito dizendo que faz̧er parte, tomar parte e ter parte indiciam que "existem diferenças na qualidade da participação" (p. 22) e exemplifica:

Possivelmente, a insatisfação com a democracia representativa que se nota nos últimos tempos em alguns países se deva ao fato de os cidadãos desejarem cada vez mais tomar parte no constante processo de tomada nacional de decisões e não somente nas eleições periódicas. A democracia participativa seria então aquela em que os cidadãos sentem que, por fazerem parte da nação, têm parte real na sua condução e por isso tomam parte cada qual em seu ambiente - na construção de uma nova sociedade da qual se sentem parte (p. 23. sic. grifos do autor).

As concepções do autor vão ao encontro da discussão que gostaríamos de tangenciar da democracia participativa, mas que suscita já de início ao questionamento, cabe a participação infantil na vida democrática? Ou melhor, no que diz respeito à participação infantil na vida democrática, como podem as crianças tomarem parte do que historicamente é concebido como algo do qual não fazem parte (a vida política)?

O autor apresenta outra passagem que, na nossa compreensão, contempla e auxilia o refinamento do olhar direcionado às práticas participativas das crianças em contexto democrático, ao qualificar os níveis de exercício de cidadania. Bordenave (1994, p. 22) afirma, "é possível fazer parte sem tomar parte e é que a segunda expressão representa um nível mais intenso de participação. Eis a diferença entre participação passiva e participação ativa, a distância entre o cidadão inerte e o cidadão engajado". Ou seja, muitos de nós fazemos parte do estado democrático de direito, mas nem por isso tomamos parte dele como cidadãos ativos. $\mathrm{E}$ as crianças? Qual nível de participação e de cidadania está sendo esperado e oportunizado para elas?

No que compete especificamente à participação infantil, o conceito do qual gostaríamos de tomar parte é o definido por Tomás e Gama (2011, p. 3), em que,

Participar significa influir diretamente nas decisões e no processo em que a negociação entre adultos e crianças são fundamentais, um processo que possa integrar tanto as divergências como as convergências relativamente aos objectivos pretendidos e que 
resultam num processo híbrido. A participação é um processo gradual, mas seguro, que se pretende, pela experiência e pela aprendizagem da participação das crianças seja [...] um direito fundamental da infância no reforço dos seus valores democráticos (sic.).

Esta definição abrangente e aberta enseja pontos para muitas reflexões, como: da negociação entre adultos e crianças; da afirmação que os resultados dos processos participativos podem ser híbridos; que a participação deve ser vivenciada pelas crianças no sentido ampliado do entendimento de experiência, e que não é, e nem deve ser naturalizada, por isso requer ser entendida pela perspectiva das aprendizagens, como ação que precisa ser apreendida pelas crianças, de diferentes formas. Percebe-se que, mesmo havendo um destaque para aprendizagem, não há um direcionamento desta a partir da consigna do ensino, pois ela é requerida enquanto experiência. O último aspecto que colocamos em relevo são os valores democráticos, que, segundo as autoras, precisam ganhar reforço, enquanto direito das crianças.

Considerar a forma como as crianças adquirem direitos é uma encruzilhada com várias intersecções, uma delas, e que cabe destaque, são as discussões da Política de Reconhecimento ${ }^{3}$, pois, por mais inseridas, engajadas, emancipadas e participativas que as crianças possam ter sido e sejam, não se auto outorgam os próprios direitos, estão em relação dialética com o outro. Esse outro, por vezes, pode ser o opressor, como aquele que cerceia e nega esses direitos. Tal como na luta pela conquista do direito das mulheres ao sufrágio, como conta a ativista do movimento de mulheres negras Ângela Davis, adveio do reconhecimento por outros - adultos/homens, de suas lutas e argumentos, no caso dos direitos das mulheres negras, muitas vezes esse outro, além de ser homem era branco (DAVIS, 2016).

Sendo assim, estamos a falar de direitos conquistados para as crianças com bem pouca presença delas próprias, de suas formas de luta, de burla, reivindicações e argumentos, entre eles o choro, forma legítima de reivindicação e expressão, como as manifestações de corpo inteiro, e da própria linguagem, como capacidade de narrar por diferentes meios e formas, que podem ser vistas e se concretizam nas culturas infantis.

Adentrar na qualificação dos direitos infantis, nesse momento histórico, significa dirigir a atenção para aqueles direitos até pouco tempo desconsiderados, ou não garantidos, os direitos políticos e civis. Pois, ao contrário do movimento de luta pela garantia dos direitos no mundo adulto, que segundo T. H. Marshall (1967) se iniciam pela conquista dos direitos civis e trabalhista, partem para os políticos, para, por fim, chegar à conquista dos direitos sociais. Ele os divide segundo gerações de direitos, de acordo com o tempo e forma que foram sendo adquiridos. Nesse argumento de "evolução" dos direitos, há uma contradição inerente, pois, dentro da perspectiva liberal na qual o exercício desses direitos vai ganhar vida, ou não, os mesmos passam a ser concebidos como "concessões", como benesses para protegidos e tutelados, perdendo sua potência de conquista, para tornarem-se uma "alternativa ao direito" (BENEVIDES, 1994).

O movimento pelos direitos infantis parece não seguir a mesma trajetória "evolucional". No Brasil, desde a reabertura do país para estado democrático de direitos, até os dias de hoje, as reivindicações

${ }^{3}$ Segundo Mendonça (2016) o conceito de reconhecimento tornou-se central nas discussões políticas contemporâneas sobre justiça, a partir da articulação entre igualdade e diferença, que permite complexificar formas simplistas de classificação das desigualdades tidas como injustas e como maléficas à democracia. O debate em torno do conceito de reconhecimento a partir dos anos de 1990 promoveu a popularização e diversificação da categoria, que "tornou-se um termo genérico que articula diversas perspectivas de justiça classificadas como críticas e preocupadas com o desvelamento das profundas exclusões existentes que minam a efetividade democrática" (p. 289). 
pela garantia mínima dos direitos sociais das crianças têm sido diuturnas. Garantir-lhes saúde, educação, assistência social, acesso à cultura, entre outros direitos sociais, tomaram conta da agenda de reivindicações da sociedade civil, dos movimentos sociais, associações comunitárias e Organizações Não Governamentais por muito tempo. Talvez seja possível supor, e arriscar dizer, que só a partir de uma garantia mínima do atendimento a esses direitos sociais, possa ter surgido a agenda de reivindicações em nome das crianças e por elas próprias, rumo aos seus direitos políticos e civis.

Pensar, promover e defender, paralelamente aos direitos sociais, os direitos políticos e civis para crianças pequenas origina-se da incorporação da mudança paradigmática de nossos conceitos e representações de infância, deixando de ter a dependência das crianças como principal justificativa para todos os nossos atos em sua direção, passando a considerá-las como sujeitos que pensam, se expressam, tem opiniões próprias, capacidade de agir e de se articularem coletivamente. Pelo avanço desse paradigma, passamos a considerar a relação entre Proteção e Participação de forma dialética (QVORTRUP, 2015). Sobre isso, Fernandes (2009) alinha a temática do debate dos direitos à perspectiva de entendimento de respeito e compreensão das potencialidades das crianças,

A defesa de um paradigma que associe direitos de proteção, provisão e participação de uma forma interdependente, ou seja, que atenda à indispensabilidade de considerar que a criança é um sujeito de direitos, que, para além da proteção, necessita de margem de acção e intervenção no seu quotidiano, é a defesa de um paradigma impulsionador de uma cultura de respeito pela criança cidadã: de respeito pelas suas vulnerabilidades, mas de respeito, também, pelas suas competências. (Fernandes, 2009, p. 48. sic)

Para retratar a licitude de tais direitos, também recorre-se ao documento da Convenção sobre os Direitos das Crianças (ONU, 1989), a Convenção ocorrida em New York é esquadrinhada com afinco por Fernandes (2009) em sua tese de doutorado intitulada "Infância, Direitos e Participação: representações, práticas e poderes", em que, entre outras coisas, dá evidência à forma como os direitos podem ser agrupados nas categorias de:

Direitos de Provisão - implicam a consideração de programas que garantam os direitos sociais da criança, nomeadamente o acesso de todas à saúde, à educação, à segurança, à vida familiar, ao recreio, à cultura.

Direitos de Proteção - implicam a consideração de uma atenção diferenciada às crianças e de um conjunto de direitos acrescidos, de que, por motivos diversos, nomeadamente situações de discriminação, abuso físico e sexual, exploração, injustiça e conflito, se encontram privadas ou limitadas no exercício dos seus direitos.

Direitos de Participação - implicam a consideração de uma imagem de infância activa, distinta da imagem objeto das políticas assistencialistas, à qual estão assegurados direitos civis e políticos, nomeadamente o direito da criança a ser consultada e ouvida, o direito ao acesso à informação, à liberdade de expressão e opinião e o direito a tomar decisões em seu benefício, direitos que deverão traduzir-se em ações públicas a ela direcionadas que considerem o seu ponto de vista (FERNANDES, 2009. p. 41-42. sic. grifos da autora).

Pode-se dizer que a articulação dessas categorias de direitos permite visualizar em que medida esses preceitos têm sido compreendidos e garantidos, tanto em um contexto social ampliado em que as crianças estão inseridas, quanto por sua compreensão e emprego dentro da área de Educação Infantil. Ou seria um equívoco buscar tais princípios em estreita relação com a prática educativa na primeira infância? Acredita-se que não. 
Dos 54 artigos do documento da CDC, não facultativos aos países-membros ou signatários da Organização das Nações Unidas, três tratam especificamente sobre os direitos que fomentam a participação infantil, ou apresentam os condicionantes inerentes ao ato da participação, como: a livre opinião, a liberdade de expressão e direito de associação, disposto assim:

\section{Artigo 12}

1. Os Estados Partes garantem à criança com capacidade de discernimento o direito de exprimir livremente a sua opinião sobre as questões que lhe respeitem, sendo devidamente tomadas em consideração as opiniões da criança, de acordo com a sua idade e maturidade.

\section{Artigo 13}

1. A criança tem direito à liberdade de expressão. Este direito compreende a liberdade de procurar, receber e expandir informações e ideias de toda a espécie, sem considerações de fronteiras, sob forma oral, escrita, impressa ou artística ou por qualquer outro meio à escolha da criança.

Artigo 15

1. Os Estados Partes reconhecem os direitos da criança à liberdade de associação e liberdade de reunião pacífica (ONU, 1989, p. 10 - 11).

A interpretação de direitos é um campo controverso, pois toda vez que sua leitura abre margem passível à interpretações diferenciadas, os direitos podem ser flexibilizados tanto para seu cumprimento quanto para seu descumprimento. Contudo, dois pontos dos artigos nos fazem pensar sobre como entendêlos e tencioná-los pela perspectiva infantil, tal como no artigo 12, quando diz que as crianças podem exprimir suas opiniões sobre questões que lhes dizem respeito, pode não ser evidente para alguns que quem escolhe o que lhes diz respeito, ou não, são as próprias crianças. Como, por exemplo, para as crianças, sexualidades pode lhes interessar, e, para tanto, podem exprimir diferentes opiniões sobre o tema.

Entretanto, sabemos que ainda hoje, esse tema tem sido censurado da área da educação como um falso tabu, vide o atual debate, ou melhor, caça às bruxas, sobre o que discurso conservador vem instituindo como "ideologia de gênero", que deu-se desde a construção dos Planos Estaduais e Municipais de Educação pelo Brasil afora, em que a temática de gênero e sexualidade foi "suprimida". O mesmo pode ser questionado quanto ao termo "pacífico" no artigo 15. Cabendo a pergunta, pacífico para quem? O entendimento de pacífico para crianças é o mesmo que para adultos?

Ainda que a CDC cumpra, em si, a função primordial da consagração dos direitos das crianças, ela tem a função de fomentar a criação de regulação em jurisprudência própria e específica em cada país. No caso brasileiro, serviu de ponto de partida para a elaboração do Estatuto da Criança e do Adolescente ECA (1990). Mesmo se tratando de um documento de quase três décadas, a CDC ainda é passível de cotejamento por diferentes perspectivas analíticas, que vão de sua abrangência, das omissões, da forma e da própria exequibilidade da CDC. Mas, para quaisquer tipos de considerações que sejam feitas, as assertivas de Lansdwon (1998) fazem-se considerar, como: que os artigos precisam ser vistos de forma articulada, não olhando para o artigo 12 de forma isolada ou estabelecendo uma hierarquia entre eles.

O mesmo autor afirma que, em seu conjunto, os direitos constituem uma filosofia relativa ao respeito dos direitos das crianças em sua qualidade como seres humanos, reconhecendo a unicidade de cada criança tanto por suas características, como por seus interesses e necessidades (LANSDWON, 1998). Quando o autor profere que os direitos foram estabelecidos a partir da compatibilidade das necessidades da 
sociedade ocidental de formar uma nova geração com competência e destreza para participar desde de pequena das sociedades democráticas, encontramos em sua fala a contemplação da forma que pensamos a validade e o caráter propositivo que o documento ainda enseja.

O que é premente considerar, a partir dos excertos que se originam da CDC, é o papel atribuído à participação infantil, enquanto cidadania participativa. Para tanto, reputa-se à participação valor em si mesma, pois passa a constituir-se como condição para efetivar o discurso que impulsiona os direitos. Dessa forma, "a promoção dos direitos de participação assume-se como imperativos para concretizar a ideia da criança como sujeito de direitos” (GAMA e TÓMAS, 2011, p. 2). Nessa mesma direção, Trevisan (2015) argumenta que "a participação permanece um foco central da cidadania, uma vez que diz respeito não apenas ao direito em si, mas ainda à possibilidade de fazer parte de um coletivo" e de ter a oportunidade de fazerem suas vozes e pontos de vista serem considerados (2015, p. 6).

Visamos anunciar que, para que se aspire que o debate democrático e as práticas democráticas façam parte do cotidiano do universo infantil, e tenha como um de seus principais lócus a instituição dedicada à primeira infância, é necessário que avancemos na articulação das discussões entre a Educação Infantil enquanto política educacional, enquanto política pública e direito social, e os princípios democráticos, entre eles a participação social. Aprofundar no entendimento sobre a participação infantil, filosófica e politicamente, pode ser a chave para uma transformação das relações e práticas, ainda antidemocráticas, vivenciadas em algumas escolas de Educação Infantil. Acreditamos que dedicar-se a construção da Pedagogia da Infância que tenha intencionalidade democrática participativa, se inicie na reconstrução do contexto educativo das crianças pequenas, com a participação ativa delas.

Amparada nesse olhar sobre os marcos legais que regulam e sustentam um conjunto de práticas junto à infância e às crianças, nos cabe dentro do âmbito da Educação Infantil, buscar por uma síntese, mesmo que parcial, que diferencie a democratização da e na Educação Infantil, e aponte para que trilhemos os caminhos da democratização com ela, com protagonismo para a participação das crianças.

Defendemos que as discussões sobre o acesso e permanência das crianças na Educação Infantil, sua ampliação e qualificação, versam sobre a democratização da etapa educacional, enquanto oferta de uma política pública. Já a democratização inerente a ela, ou seja, dentro de sua estrutura de funcionamento, enquanto princípio orientador das ações, pode se dar tanto pela ideia de difusão dos conhecimentos, mas também das materialidades e oportunidades; assim como no campo da democratização da gestão da coisa pública e das relações de poder entre os adultos, que, por vezes, consideram as crianças, mas na maioria das vezes, ainda não. Essa democratização na Educação Infantil é das formas, das práticas, das relações cotidianas entre os sujeitos, do direito a tomar parte e ter parte, buscando romper com a lógica hierarquizada da forma de organização e das relações pedagógicas inerentes às instituições de Educação Infantil. 


\section{Continuidades}

Dentro da área de Educação Infantil avançamos no debate acerca da caracterização da instituição dedicada à educação das meninas e meninos de 0 a 5 anos de idade. Hoje o termo escola, tal como dado historicamente, que passou do acesso por poucos (meninos das classes abastadas), para uma ampla expansão (impulsionada por diferentes motivos) em busca da universalização do atendimento, que nem sempre foi e é sinônimo de democratização, e sim de uma massificação, lhe atribui características homogeneizantes de currículo, estruturação organizacional, gestão e até de padrões arquitetônicos, que refletem pouco os sujeitos do processo educativo. O que tornou as escolas impessoais e frias, como se estivessem estacionadas no tempo. Foi essa forma, a partir de uma única fôrma, que difundiu-se como escola obrigatória na sociedade ocidental, sendo apropriada pelo senso-comum, estereotipada pelos veículos de comunicação de massa e cooptada pelo mercado neoliberal como uma linha de produção.

Esse modelo escolar não representa, e não diz respeito ao que hoje se concebe como instituição educacional dedicada à primeira infância. Por esse e outros motivos, o termo escola se distanciou de representar o lócus onde se desenvolvem as práticas educacionais com crianças de 0 a 5 anos de idade, pois também não se trata de quaisquer práticas, mas especificamente de uma Pedagogia da Infância. Mas não só, a concepção de infância, ou a maneira como ela é entendida, se, como um vir-a-ser ou como ator social competente, condiciona ao entendimento e configuração da instituição educacional dedicada à elas (DAHLBERG; MOSS; PENCE; 2003).

Nesta perspectiva, pensar a configuração de uma escola democrática dedicada à primeira infância pode tornar a tarefa, por um lado, muito complexa, dada as especificidades da faixa etária das crianças, como por outro lado não. Primeiro porque não compete apenas em uma adaptação do já instituído nas outras etapas educacionais. Afinal, defende-se que nunca deveria ter sido assim, uma adaptação, uma forma ajustada da escola obrigatória de Ensino Fundamental em tamanho reduzido e infantilizada, pejorativamente, para a Educação Infantil. Em contexto democrático, muito menos. Não há um modelo ou fórmula a ser seguida, mas intencionalidade e um conjunto de práticas que vão sendo acordadas e instituídas paulatinamente de forma negociada, reflexiva e flexível, deixando margem cabível para os constantes aperfeiçoamentos, por isso ela é pensada com a Educação Infantil, e seus atores sociais.

Gostaríamos, no entanto, de argumentar que, apesar da complexidade de imaginar a concretização, ou mesmo a concepção de como seria uma outra escola democrática, dedicada especialmente às crianças pequenas, onde elas protagonizem a auto-gestão, a livre expressão, a desterritorialização, vivenciem as diferenças e diversidades, sejam críticas e participativas, alguns passos já têm sido dados nessa direção. Ver-se que as pesquisas acadêmicas da área da Educação Infantil já vêm avançando paulatinamente nesse sentindo, se contrapondo ao modelo hegemônico, avançado nas discussões de suas especificidades, contribuindo com a construindo uma Pedagogia própria, pensando as questões micro e macro de forma relacional, tendo a infância como potente e dando primazia aos sujeitos, em especial às crianças. Vemos que já saímos de um terreno arenoso para um solo fértil de possibilidades de mudanças, de novas/outras configurações de organização da instituição educativa, para além do modelo 
escolar, sem com isso abrir mão das intencionalidades educativas, que nesse momento, tais intencionalidades urgem serem declaradamente democráticas.

Mesmo circunscrevendo o debate dentro de um panorama sucinto, acreditamos que ele auxilia a abrir um campo de visão, de problematizações, possibilidades, potências, e de perturbação de uma ordem dada, para apontar que outras formas de fazer e pensar a Educação Infantil são viáveis, desejáveis e urgentes. Dentro da perspectiva teórica e política que estamos acreditando, a democrática, não é possível estabelecer um roteiro como guia a ser implementado e seguido rumo a práticas democráticas nas instituições dedicadas à primeira infância, isso iria contra o ideário defendido, de que, em processos democráticos, os atores constroem seus próprios percursos, neste caso, em específico, os principais atores são as crianças de 0 a 5 anos de idade, e é essa a nossa principal defesa, de que eles e elas sejam partícipes da construção de uma outra configuração não só de instituição educacional, mas também da própria sociedade e da democracia.

\section{Referências}

AGOSTINHO, Kátia A. Formas de participação das crianças na Educação Infantil. Tese de Doutorado em Estudos da Criança. Braga (Portugal): Universidade do Minho. 2010.

BARBOSA, Ma Carmen S.; DELGADO, Ana Cristina Coll; TOMÁS, Catarina Almeida. Estudos da Infância, Estudos da Criança: Quais campos? Quais questões? Quais métodos? Inter-Ação. Goiânia, v. 41, n. 1, p. $103-122$, jan/abr, 2016

BARBOSA, Ma Carmen. Mapeando alguns desafios para as políticas públicas de Educação Infantil no Brasil. In: VASQUES, Carla K.; SHILICKMANN, Mª Sirlene,; CAMPOS, Rosânia (orgs.). Educação e Infância: múltiplos olhares, outras leituras. Ed. Unijuí: Ijuí (SC), 2009. p.169 - 180.

BARNER, B. Understanding agency: social theory and responsible action. London: Sage, 2000.

BENEVIDES, Mª Victoria de M. A cidadania ativa: referendo, plebiscito e iniciativa popular. $3^{a}$ ed. São Paulo: Editora Ática, 2003.

BORDENAVE, Juan E. D. O que é participação. 6a ed. São Paulo: Editora Brasiliense. 1994.

BOURDIEU, Pierre. Campo Intelectual e Projeto Criador. In: POUILLON. J. (org.) Problemas do Estruturalismo. pp. 17- 38. Rio de Janeiro: Zahar, 1968.

BRASIL. Constituição da República Federativa do Brasil. Lei federal de 5/10/1988. Brasília (DF): Senado Federal, 2000. 
BRASIL. Estatuto da Criança e do Adolescente (ECA).Lei n. ${ }^{\circ} 8.069$ de 13 de julho de 1990.

BRASIL, Conselho Nacional de Educação. Resolução $\mathbf{n}^{\circ} 05$ da Câmara de Educação Básica que estabelece as Diretrizes Curriculares Nacionais para Educação Infantil. Brasília: MEC, 2009.

CAMPOS, Maria Malta. As políticas públicas de educação infantil no contexto da nova legislação educacional brasileira. Educação em Debate, São Paulo, n. 1, p. 21 - 36, 1998.

CANAVIEIRA, Fabiana O. A Educação Infantil no olho do furacão: o movimento político e as contribuições da Sociologia da Infância. Dissertação de Mestrado. Campinas: Faculdade de Educação da UNICAMP, 2010.

COUTINHO, Ângela Maria Scalabrin. A ação social dos bebês: um estudo etnográfico no contexto da creche. Braga (Portugal): Universidade do Minho, 2010.

COUTINHO, Nelson. A democracia como valor universal: notas sobre a questão democrática no Brasil. São Paulo: Livraria Editora Ciências Humanas, 1980.

DAVIS, Angela. Mulher, raça e classe. $1^{a}$ ed. São Paulo: Bointempo, 2016.

FERNANDES, Natália. Infância, Direitos e Participação: representações, práticas e poderes.Porto/Portugal: Edições Afrontamento, 2009.

FRANZONI, Juliana Ribeiro Alves. Gestão Democrática e práticas participativas na Educação Infantil: um estudo de caso numa creche pública municipal. Dissertação de Mestrado. Florianópolis: UFSC, 2015.

GIDDENS, Anthony. A constituição da sociedade. $2^{a}$ Ed. São Paulo: Martins Fontes, 2003.

GIDDENS, A.; TURNER, Jonathan (orgs.). Teoria Social Hoje. p. 7-47. São Paulo: Editora Unesp, 1999.

HART, R. Participação de Crianças: da indicação falsa até a cidadania. UNICEF, 1992.

LANSDOWN, Gerison. La creación de escuelas centradas en el nino. In: Actas do congresso La participación de niños y adolescentes en el contexto de la Convención sobre los Derechos del Niño: visiones y perspectivas. Bogotá: UNICEF, 1998, p. 59-70. 
¿Me haces caso? El derecho de los niños pequeños a participar en las decisiones que los afectan. Cuadernos sobre Desarrollo Infantil Temprano. No. 36s. fundacion Bernard Van Leer, La Haya, Paese Bajo, 2005.

MARSHALL, T. H. Cidadania, classe social e status.Rio de Janeiro: Zahar, 1967.

MASSCHELEIN, J.; SIMONS, Maarten. A pedagogia, a democracia, a escola. Belo Horizonte: Autêntica, 2014.

MENDONÇA, Ricardo F. Reconhecimento, desigualdade e capitalismo. In: MIGUEL, Luis Felipe (org.). Desigualdades e Democracia: o debate da teoria política. São Paulo: Editora Unesp, p. 287 - $322,2016$.

MOSS, Peter. Introduzindo a política na creche: a educação infantil como prática democrática. Revista Psicologia. São Paulo: USP, vol.20, no.3, p. 417 - 423, jul./set. 2009.

Portare le Politiche nei servizi educativi: L’educazione nella prima infanzia come pratica di democrazia.1ª Bologna (Itália): GruppNazionaleNidi e Infanzia, 2013.

ORGANIZAÇÕES DAS NAÇÕES UNIDAS. Convenção sobre os Direitos das Crianças. 1989. Disponível em: http://www.onu-brasil.org.br/doc crianca.php. Acesso em: 08 de fevereiro de 2016.

PIRES, Sergio F. S.; BRANCO, Angela U. Protagonismo infantil:co-construindo significados em meio ás práticas sociais. Paidéia, v. 17, n. 38, 2007, p. 331 - 320.

QVORTRUP, Jens. Infância e Política. Caderno de Pesquisa, v.40, n. 141, p.777 - 792, Set/Dez, 2010.

QVORTRUP. Jens. A dialética entre a proteção e a participação. Revista Currículo sem Fronteiras, v. 15, n.1, p. 11 - 30, jan/abri. 2015.

ROSEMBERG, FÚLVIA. Sísifo e a educação infantil brasileira. Pró-posições, v. 14, nº 1 (40), 2003 , p. $177-194$.

SARMENTO, Manoel J. Visibilidade Social e Estudos da Infância. In: VASCONCELOS, Vera (org). Infância (in)visível. Araraquara/SP: Junqueira \& Marin, 2007, p. 25 -52.

SARMENTO, Manoel J.; ABRUNHOSA, Albertina; FERNANDES, Natália. Participação Infantil na organização escolar. In: QUINTEIRO, Jucirema; CARVALHO, Diana de C (orgs.). Participar, brincar e aprender: os direitos das crianças na escola. Araraquara/SP: Junquera\& Marin; Brasília: CAPES, 2007. p. 51- 90. 
TOMÁS, Catarina; GAMA, Ana. Cultura de (não) participação das crianças em contexto escolar. Porto (Portugal), 2011. In: Anais. Educação, Território e (Des)igualdades. II Encontro de Sociologia da Educação. Disponível in: http://repositorio.ipl.pt/bitstream/10400.21/1116/1/Cultura\%20de\%20(n\%C3\%A3o)\%20participa\%C3 $\% \mathrm{~A} 7 \% \mathrm{C} 3 \% \mathrm{~A} 3 \mathrm{o} \% 20 \mathrm{das} \% 20 \mathrm{crian} \% \mathrm{C} 3 \% \mathrm{~A} 7 \mathrm{as} \% 20 \mathrm{em} \% 20$ contexto $\% 20$ escolar.pdf Acesso em: 03.04. 2017.

TREVISAN, Gabriela de Pina. Somos as pessoas que temos de escolher, não são as outras pessoas que escolhem por nós. Infância e cenários de participação: uma análise sociológica dos modos de codecisão das crianças na escola e na cidade. Tese de Doutoramento. Braga: Universidade do Minho, 2014. 